OPEN ACCESS

Edited by:

Yongqian Shi,

Fuzhou University, China

Reviewed by:

Gang Tang,

Anhui University of Technology, China Yuezhan Feng,

Zhengzhou University, China

Chuyuan Huang,

Wuhan University of Technology,

China

Wenzong $X u$

Anhui Jianzhu University, China

*Correspondence:

Qinghong Kong

kongqh@mail.ujs.edu.cn

Junhao Zhang

mailto:jhzhang6@just.edu.cn

Specialty section:

This article was submitted to Polymeric and Composite Materials,

Geomorphology and

Paleoenvironment,

a section of the journal

Frontiers in Materials

Received: 29 July 2020

Accepted: 24 August 2020

Published: 22 September 2020

Citation:

Kong $Q$, Zhang $C$, Zheng $G$, Zhang $M$,

Zhou T, Zhang J, Guo $X$ and Cai $Y$

(2020) Effect of Graphene

Oxide-Modified Cobalt Nickel

Phosphate on Flame Retardancy of

Epoxy Resin.

Front. Mater. 7:588518.

doi: 10.3389/fmats.2020.588518

\section{Effect of Graphene Oxide-Modified Cobalt Nickel Phosphate on Flame Retardancy of Epoxy Resin}

\author{
Qinghong Kong ${ }^{1 *}$, Caijiao Zhang ${ }^{1}$, Guolin Zheng ${ }^{1}$, Manman Zhang ${ }^{1}$, Tao Zhou ${ }^{1}$, \\ Junhao Zhang ${ }^{2 *}$, Xingmei Guo ${ }^{2}$ and Yibing Cai ${ }^{3}$ \\ ${ }^{1}$ School of the Environment and Safety Engineering, Jiangsu University, Zhenjiang, China, ${ }^{2}$ School of Environmental and \\ Chemical Engineering, Jiangsu University of Science and Technology, Zhenjiang, China, ${ }^{3}$ Key Laboratory of Eco-textiles, Ministry \\ of Education, Jiangnan University, Wuxi, China
}

Synergistic effect is an effective strategy for improving the flame retardancy of epoxy resin $(E P)$. In this work, a novel graphene oxide-cobalt nickel phosphate $\left(\mathrm{GO}-\mathrm{NiCoPO}_{3}\right)$ is successfully synthesized, which is incorporated into an EP matrix for preparing EP/GO$\mathrm{NiCoPO}$ nanocomposites. The results show that the limiting oxygen index value of EP/ $4 \mathrm{GO}-\mathrm{NiCoPO}$, nanocomposites is as high as $30.3 \%$, and UL-94 can reach $\mathrm{V}-1$ rating. The results of micro-combustion calorimetry indicate that the total heat release value and peak of heat release rate of $\mathrm{EP} / 8 \mathrm{GO}-\mathrm{NiCoPO}_{3}$ nanocomposites are decreased by 41.9 and $23.8 \%$ compared with those of pure EP. This is mainly due to the synergistic barrier effect of $\mathrm{GO}$ and $\mathrm{NiCOPO}_{3}$, which together have their own advantages. Meanwhile, EP/GO$\mathrm{NiCOPO}{ }_{3}$ nanocomposites can form a dense char layer during the burning process and improve the thermal stability of $\mathrm{EP} / \mathrm{GO}-\mathrm{NiCOPO}_{3}$ nanocomposites.

\footnotetext{
Keywords: epoxy resin, graphene oxide-cobalt nickel phosphate, thermal stability, flame retardancy, synergistic barrier effect
}

\section{INTRODUCTION}

Epoxy resin (EP) is well known for its excellent mechanical and chemical properties and has been used in various fields such as electronics and insulating materials. (Kong et al., 2017a; Li et al., 2018; Xu et al., 2019; Ding et al., 2020; Nie et al., 2020). However, its severe flammability with toxic gases and smoke during combustion limits its wide application (Zhang et al., 2018; Kong et al., 2019c; Yang et al., 2019). Therefore, searching for efficient and environmentally friendly flame retardants that can reduce the flammability of EP has become the pursuit of many researchers.

In recent years, transition metals and phosphorus-containing compounds have been found to have excellent ability to catalyze the formation of char and catalyze the conversion of harmful substances, arousing wide attention of researchers (Zheng et al., 2017; Sun et al., 2018; Feng et al., 2019; Kong et al., 2019a; Zhang et al., 2019; Zhou et al., 2019). A new flame retardant (P-MnMo 6 ) was synthesized with 9,10-dihydro-9-oxa-10-phosphaphenanthrene-10-oxide (DOPO) with polyoxometalate and added to EP (Peng et al., 2020). The results demonstrated that the peak of heat release rate (PHRR) of EP/ $\mathrm{P}-\mathrm{MnMo}_{6}-4$ nanocomposites was reduced by $41 \%$ and the char yield increased significantly, and CO and smoke emissions were also greatly suppressed. In particular, the addition of ultra-thin layered nanomaterials can increase the viscosity of a polymer and form an insulating char layer during the combustion process, thereby slowing the oxygen overflow rates and reducing the amount of combustible gas (Kong et al., 2018b, Asabina et al., 2019, Kong et al., 2019b). For example, the hybrid NiFe-LDH-MoS 2 was prepared by a simple self-assembly method and blended into EP to 
prepare $\mathrm{EP} / \mathrm{NiFe}-\mathrm{LDH}-\mathrm{MoS}_{2}$ nanocomposites. When $2 \mathrm{wt} \%$ $\mathrm{NiFe}-\mathrm{LDH}-\mathrm{MoS}_{2}$ was added to EP, the PHRR and total heat release (THR) values were reduced by 66 and 34\%, respectively. The output of smoke and toxic gas, such as $\mathrm{CO}$ and $\mathrm{CO}_{2}$, was significantly reduced (Zhou et al., 2017). A multifunctional nanohybrid $\left(\mathrm{Ti}_{3} \mathrm{C}_{2} \mathrm{~T}_{\mathrm{x}} @ \mathrm{MCA}\right)$ was prepared by interacting titanium carbide nanosheets $\left(\mathrm{Ti}_{3} \mathrm{C}_{2} \mathrm{~T}_{\mathrm{x}}\right.$, MXene) with melamine cyanurate (MCA) via hydrogen bonding interactions. The significantly improved mechanical and fire-safe performances of TPU/ $\mathrm{Ti}_{3} \mathrm{C}_{2} \mathrm{~T}_{\mathrm{x}} @ \mathrm{MCA}-3.0$ were superior to those of thermoplastic polyurethane (TPU) nanocomposites filled with other nanoadditives (Shi et al., 2020). Therefore, it is possible that layered transition metal phosphide flame retardants could be prepared together with catalytic transition metals and phosphorus element, and applied to polymers, which will inevitably improve the flame retardancy of macromolecule polymers.

Graphene has attracted more and more attention in the flame retardancy of polymers due to its high specific surface area, thermal stability, and unique 2D structure (Cote et al., 2011; Yu et al., 2015; Cai et al., 2016; Xu et al., 2019). In particular, graphene oxide (GO), which has organic groups such as $-\mathrm{OH}$, - $\mathrm{COOH}$, and $\mathrm{C}-\mathrm{O}$, can enhance compatibility with a polymer matrix, thereby improving dispersibility in the polymer matrix (Huang et al., 2011; Kong et al., 2018a; Yue et al., 2019). DOPO was covalently bonded to GO and added to an EP matrix for preparing EP/DOPO-rGO nanocomposites. When $10 \mathrm{wt} \%$ DOPO-rGO was added, the char yield and limiting oxygen index (LOI) value were increased by 81 and 30\%, respectively, and obviously improved the flame retardancy of the EP (Liao et al., 2012). A multifunctional hydrophilic graphene-based

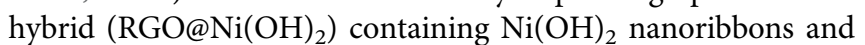
reduced GO (RGO) was synthesized, and hexagonal boron nitride sheets were simultaneously added into an EP matrix.

The PHRR, THR, and total smoke production values of EP/ hexagonal boron nitride/RGO@Ni(OH)$)_{2}$ nanocomposites were reduced by $33.5,33.8$, and $43.0 \%$, respectively (Feng et al., 2020). A new graphene-based inorganic-organic hybrid flame retardant (GFR) was prepared by hybridization of functionalized GO and phenyl-bis-(triethoxysilylpropyl) phosphoramide; only with the addition of $1 \mathrm{wt} \%$ GFR in EP, the char yield was increased by $10.4 \%$, and the PHRR and THR values were decreased by 43 and 44.7\%, respectively (Mu et al., 2016).

Therefore, in combination with literature analysis, a type of ultrathin flame retardant cobalt nickel phosphate $\left(\mathrm{NiCoPO}_{3}\right)$ nanoplates were successfully synthesized, which were grown on the surface of GO by the surface growth method. Then, the new hybrid flame retardant $\left(\mathrm{GO}-\mathrm{NiCoPO}_{3}\right)$ was incorporated into the $\mathrm{EP}$ matrix to prepare $\mathrm{EP} / \mathrm{GO}-\mathrm{NiCoPO}_{3}$ nanocomposites. Compared with other phosphorus-containing flame retardants, such as phosphoruscontaining silane (Tang et al., 2020b), ammonium polyphosphate (Reuter et al., 2020), phosphazene-triazine bi-group (Chen et al., 2020), aluminum diethylphosphinate (Tang et al., 2020c), melamine phenylhypophosphonate (Zhu et al., 2020), and melamine pyrophosphate (Tang et al., 2020a), GO-NiCoPO 3 has nanoscale ultra-thin layered structures, which can have a layered barrier effect in the combustion process of polymer composites, and has more organic functional groups to better integrate with polymer composites. GO-NiCoPO${ }_{3}$ has low loading in polymers; hence, when only $4 \mathrm{wt} \%$ was added to $\mathrm{EP}$, in the UL-94 tests, EP/4 GO$\mathrm{NiCoPO}_{3}$ nanocomposites passed $\mathrm{V}-1$ rating.

\section{EXPERIMENTAL SECTION}

\section{Materials}

Graphite powder (spectral pure), potassium permanganate $\left(\mathrm{KMnO}_{4}, \mathrm{AR}, \geq 99.5 \%\right)$, cobalt(II) acetate tetrahydrate $\left(\mathrm{C}_{4} \mathrm{H}_{6} \mathrm{CoO}_{4} \cdot 4 \mathrm{H}_{2} \mathrm{O}, \mathrm{AR}, \geq 99.5 \%\right)$, nickel(II) acetate tetrahydrate $\left(\mathrm{C}_{4} \mathrm{H}_{6} \mathrm{NiO}_{4} \cdot 4 \mathrm{H}_{2} \mathrm{O}, \quad \mathrm{AR}, \geq 98.0 \%\right)$, sodium pyrophosphate $\left(\mathrm{Na}_{4} \mathrm{O}_{7} \mathrm{P}_{2}, \mathrm{AR}, \geq 99.0 \%\right)$, acetone $\left(\mathrm{C}_{3} \mathrm{H}_{6} \mathrm{O}, \mathrm{AR}, \geq 99.5 \%\right)$, EP (NPEL128), and 4, 4-diaminodiphenyl methane (DDM, $\geq 98.0 \%)$ were purchased by Sinopharm Chemical Reagent Co., Ltd. Sodium nitrate $\left(\mathrm{NaNO}_{3}, \mathrm{AR}, \geq 99.0 \%\right)$ and hydrogen peroxide $\left(\mathrm{H}_{2} \mathrm{O}_{2}, \mathrm{AR}, \geq 30 \%\right)$ were purchased from Wuxi Jingke Chemical Co., Ltd. Sulfuric acid $\left(\mathrm{H}_{2} \mathrm{SO}_{4}, \mathrm{AR}, 95-98 \%\right)$ was provided by Shanghai Jutai Special Reagent Co., Ltd. All chemicals were of analytical grade purity and used without any further purification.

\section{Preparation of $\mathrm{NiCoPO}_{3}$}

$\mathrm{C}_{4} \mathrm{H}_{6} \mathrm{NiO}_{4} \cdot 4 \mathrm{H}_{2} \mathrm{O}(0.4 \mathrm{~g}), \mathrm{C}_{4} \mathrm{H}_{6} \mathrm{CoO}_{4} \cdot 4 \mathrm{H}_{2} \mathrm{O}$ (0.478 g), $\mathrm{Na}_{4} \mathrm{O}_{7} \mathrm{P}_{2}$ $(0.839 \mathrm{~g})$, and $10 \mathrm{ml}$ of water were mixed together. Then, the above mixed solution was stirred at room temperature for $30 \mathrm{~min}$ and transferred to a $100-\mathrm{ml}$ stainless steel autoclave lined with polytetrafluoroethylene heated at $180^{\circ} \mathrm{C}$ for $24 \mathrm{~h}$. The products were washed several times with water and ethanol, and dried at $80^{\circ} \mathrm{C}$ for $24 \mathrm{~h}$.

\section{Preparation of GO-NiCoPO}

GO was prepared by a modified Hummer's method ( $\mathrm{Yu}$ et al., 2017). First, $\mathrm{C}_{4} \mathrm{H}_{6} \mathrm{NiO}_{4} \cdot 4 \mathrm{H}_{2} \mathrm{O}(0.4 \mathrm{~g}), \mathrm{C}_{4} \mathrm{H}_{6} \mathrm{CoO}_{4} \cdot 4 \mathrm{H}_{2} \mathrm{O}(0.478 \mathrm{~g})$, $\mathrm{Na}_{4} \mathrm{O}_{7} \mathrm{P}_{2}(0.839 \mathrm{~g})$, and $15 \mathrm{ml}(1 \mathrm{~g} / \mathrm{l})$ of $\mathrm{GO}$ were mixed together. Then, the above mixed solution was stirred at room temperature for $30 \mathrm{~min}$ and transferred to a $100-\mathrm{ml}$ stainless steel autoclave lined with polytetrafluoroethylene heated at $180^{\circ} \mathrm{C}$ for $24 \mathrm{~h}$. The black products were centrifuged and dried under vacuum at $80^{\circ} \mathrm{C}$ for $24 \mathrm{~h}$.

\section{Preparation of Epoxy Resin/Graphene Oxide-Cobalt Nickel Phosphate Nanocomposites}

First, GO-NiCoPO 3 was added to acetone and sonicated until completely dispersed; then, EP was added to the above solution and subjected to ultrasound. The homogenous system was stirred at $90^{\circ} \mathrm{C}, \mathrm{DDM}$ was charged into the above system, and stirring was continued until DDM completely dissolved and blended vigorously for $5 \mathrm{~min}$. The homogenized samples were rapidly poured into moulds and, cured at 110,130 , and $150^{\circ} \mathrm{C} / 2 \mathrm{~h}$. The preparation procedure of pure $\mathrm{EP}$ and $\mathrm{EP} / \mathrm{NiCoPO}_{3}$ nanocomposites was exactly the same as the above process. The specific contents are shown in Table 1.

\section{Characterization}

$\mathrm{X}$-ray powder diffraction (XRD) has a graphite monochromatic diffraction line of $\mathrm{Cu} \mathrm{Ka}, \lambda=1.5418 \AA$, an operating voltage of 
TABLE 1 | Ingredients of EP nanocomposites.

\begin{tabular}{lccc}
\hline Sample & EP (wt\%) & $\left.\mathbf{G O}^{-N_{i C o P O}} \mathbf{( w t} \%\right)$ & $\mathbf{N i C o P O}_{\mathbf{3}}$ (wt\%) \\
\hline EP & 100 & 0 & 0 \\
EP/1GO-NiCoPO $_{3}$ & 99 & 1 & 0 \\
EP/2GO-NiCoPO $_{3}$ & 98 & 2 & 0 \\
EP/4GO-NiCoPO $_{3}$ & 96 & 4 & 0 \\
EP/6GO-NiCoPO $_{3}$ & 94 & 6 & 0 \\
EP/8GO-NiCoPO & 92 & 8 & 0 \\
EP/4NiCoPO $_{3}$ & 96 & 0 & 4
\end{tabular}

$E P$, epoxy resin; Go, graphene oxide; $\mathrm{NiCOPO}_{3}$, cobalt nickel phosphate.

$40 \mathrm{kV}$, and current of $100 \mathrm{~mA}$. The diffractometer was of the Japanese Rigaku MAX-RB model. Fourier transform infrared spectra (FTIR) were tested by the $\mathrm{KBr}$ tableting method, and the spectral frequency ranges from 400 to $4,000 \mathrm{~cm}^{-1}$. It is a spectrometer of the 6700 model of Nicolet Instrument Co., Ltd. Scanning electron microscopy (SEM) and Transmission electro microscopy (TEM) were used to observe the microstructures and morphology of $\mathrm{NiCoPO}_{3}$ and $\mathrm{GO}-\mathrm{NiCoPO}_{3}$. The acceleration voltage was $100 \mathrm{kV}$, and the transmission electron microscope was of the Japanese JEOL JEM-100SX model.

Thermogravimetric (TG) analysis was carried out using a TG/ DSC1 device manufactured by METTLER TOLEDO under a nitrogen atmosphere with a linear heating rate of $10^{\circ} \mathrm{C} \mathrm{min}^{-1}$. LOI measurements were performed using an oxygen index model instrument (Fire Testing Technology, United Kingdom). The spline size was $130 \mathrm{~mm}^{3} \times 6.5 \mathrm{~mm}^{3} \times 3.2 \mathrm{~mm}^{3}$ according to ASTM D 2863-97. Based on ASTM D 3801, the vertical combustion test (UL-94) was carried out in a combustion chamber (Fire Testing Technology, United Kingdom), and the spline size was $130 \mathrm{~mm}^{3} \times 12.7 \mathrm{~mm}^{3} \times 3.2 \mathrm{~mm}^{3}$. Microcombustion calorimetry (MCC) generally involved pulverizing a sample $(5 \mathrm{mg})$ in a nitrogen stream $\left(80 \mathrm{~cm}^{3} \mathrm{~min}^{-1}\right)$. The cleavage product was mixed with a stream of oxygen $\left(20 \mathrm{~cm}^{3} \mathrm{~min}^{-1}\right)$ and then burned at $900^{\circ} \mathrm{C}$. The furnace was heated to the desired temperature to obtain heat release parameters, which were measured using a MCC-2 calorimeter (Govmark, United States).

\section{RESULTS AND DISCUSSION}

\section{Structure and Performance of Graphene Oxide-Cobalt Nickel Phosphate}

The XRD is often used to investigate the lamellar structure and crystallinity of inorganic nanomaterials (Guo et al., 2020; Xue et al., 2020; Zhang et al., 2020). Figure 1A presents the XRD pattern of $\mathrm{NiCoPO}_{3}$, which reveals the characteristic peaks at $2 \theta=$
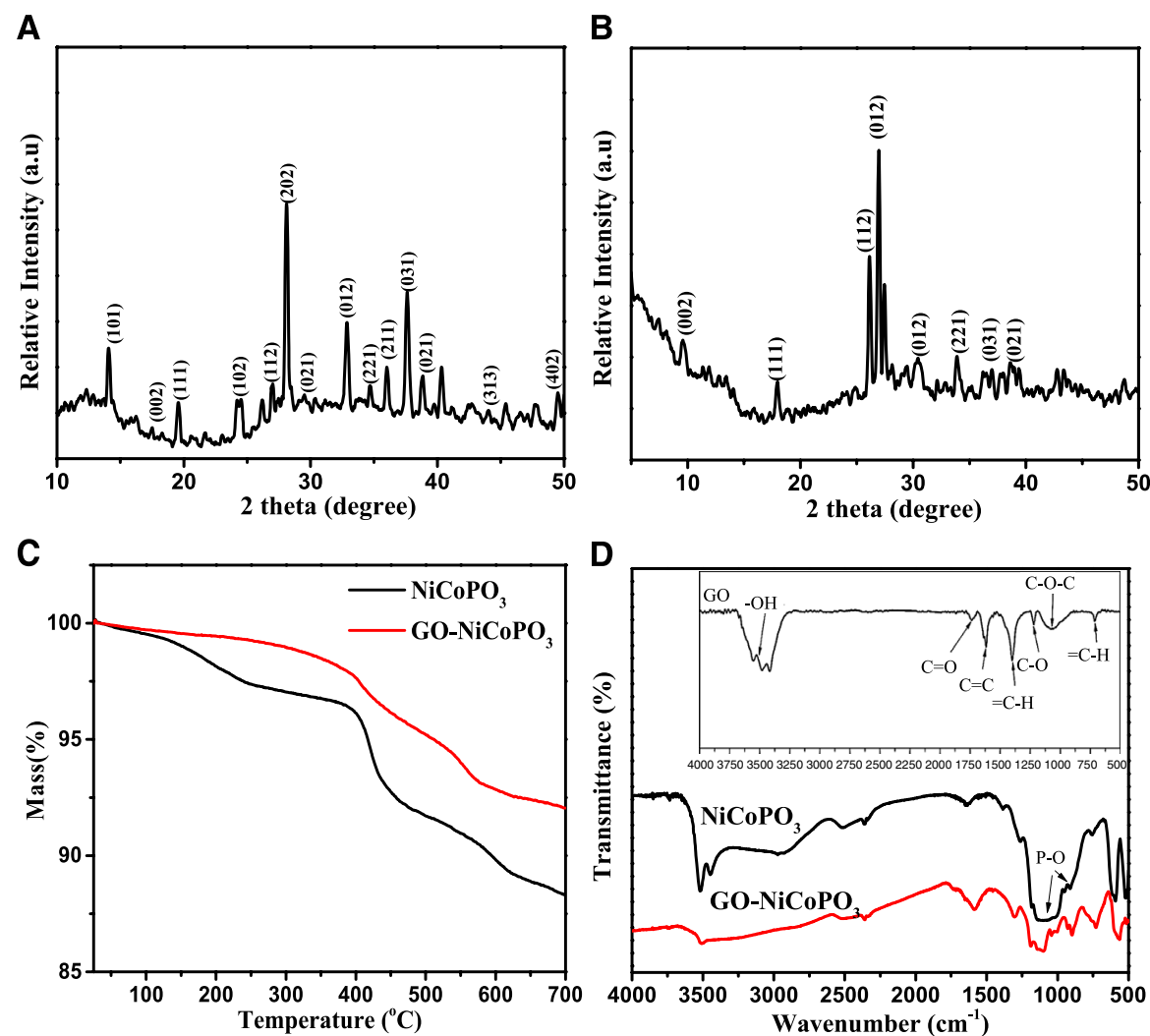

FIGURE 1 | (A) X-ray powder diffraction pattern of $\mathrm{NiCoPO}_{3}$; (B) X-ray powder diffraction pattern of $\mathrm{GO}-\mathrm{NiCoPO}$; (C) $\mathrm{TG}_{\mathrm{Cu} v e s}$ of $\mathrm{NiCoPO}$ and $\mathrm{GO}-\mathrm{NiCoPO}$; (D) Fourier transform infrared spectra spectra of $\mathrm{NiCoPO}_{3}$ and $\mathrm{GO}-\mathrm{NiCoPO}_{3}$; the inset is Fourier transform infrared spectra legend of $\mathrm{GO}$. Go, graphene oxide; NiCoPO 3 , cobalt nickel phosphate. 
$13.3^{\circ}, 17.9^{\circ}, 26.1^{\circ}, 26.7^{\circ}, 26.9^{\circ}, 27.4^{\circ}, 29.9^{\circ}, 33.8^{\circ}, 38.6^{\circ}$, and $48.5^{\circ}$, corresponding to the orders of $\mathrm{Co}_{3}\left(\mathrm{PO}_{4}\right)_{2}$ on (101), (111), (102), (112), (202), (021), (012), (221), (031), and (402) planes, respectively. Simultaneously, the diffraction peaks are observed at $2 \theta=17.5^{\circ}, 23.5^{\circ}, 26.0^{\circ}, 37.2^{\circ}$, and $39.3^{\circ}$, corresponding to the position of $\mathrm{Ni}_{3}\left(\mathrm{PO}_{4}\right)_{2}$ on the (002), (102), (111), (211), and (021) (Li et al., 2017). Figure 1B shows the XRD pattern of GO$\mathrm{NiCoPO}_{3}$, and a weak characteristic diffraction peak of GO appears at $2 \theta=9.8^{\circ}$, which may be caused by the low content of GO (Si and Samulski, 2008). GO has hydroxyl groups and carboxyl groups, and can form hydrogen bonds with the surface of $\mathrm{NiCoPO}_{3}$, making the original strong diffraction peak weak. Figure $1 \mathrm{C}$ shows the TG curves of $\mathrm{NiCoPO}_{3}$ and $\mathrm{GO}-\mathrm{NiCoPO}_{3}$. Before $200^{\circ} \mathrm{C}$, due to dehydration of $\mathrm{NiCoPO}_{3}$ nanosheets, $\mathrm{NiCoPO}_{3}$, and $\mathrm{GO}-\mathrm{NiCoPO}_{3}$ had a little weight loss. After $200^{\circ} \mathrm{C}, \mathrm{NiCoPO}_{3}$ is decomposed into metaphosphoric acid and metal oxide, and the organic groups of $\mathrm{GO}$ also begin to decompose, but the weight loss of $\mathrm{GO}-\mathrm{NiCoPO}_{3}$ is less than that of $\mathrm{NiCoPO}_{3}$ in the whole process (Zhu et al., 2010; Huang et al., 2016). The FTIR spectra of $\mathrm{NiCoPO}_{3}$ and $\mathrm{GO}-\mathrm{NiCoPO}_{3}$ are shown in Figure 1D, and the FTIR legend of GO is embedded in the inset. The peak of $3,500 \mathrm{~cm}^{-1}$ corresponds to the $-\mathrm{OH}$ stretching vibration of $\mathrm{NiCoPO}_{3}$, and the characteristic peaks of the P-O structure are $1,182,1,174$, and $938 \mathrm{~cm}^{-1}$. For GO$\mathrm{NiCoPO}_{3}$ nanosheets, the peak at $1,782 \mathrm{~cm}^{-1}$ corresponds to the chary $\mathrm{C}=\mathrm{O}$ stretching vibration peak. The peak at $1,434 \mathrm{~cm}^{-1}$ corresponds to the epoxy group $\mathrm{C}-\mathrm{O}$, and the peak at $1,055 \mathrm{~cm}^{-1}$ corresponds to the alkoxy $\mathrm{C}-\mathrm{O}$ telescopic vibration peak. This further illustrates the successful preparation of $\mathrm{GO}-\mathrm{NiCoPO}$.
In order to understand the morphology and microstructure of the product in more detail, SEM and TEM tests were performed. The SEM image of $\mathrm{NiCoPO}_{3}$ is presented in Figure 2A, which shows that $\mathrm{NiCoPO}_{3}$ has an irregular layered structure of $100-200 \mathrm{~nm}$. As can be seen from Figure 2B, the surface of GO is wrinkled, and the nanometer scale is about $500 \mathrm{~nm}$ (Stobinski et al., 2014). Figure 2C shows the SEM image of $\mathrm{GO}-\mathrm{NiCoPO}_{3}$. It can be seen that the lamellar structure is darker than $\mathrm{NiCoPO}_{3}$, probably due to the addition of GO to the surface of $\mathrm{NiCoPO}_{3}$. Figure 2D shows the TEM image of GO$\mathrm{NiCoPO}_{3}$. The morphology of $\mathrm{GO}-\mathrm{NiCoPO}_{3}$ is substantially smooth and flat, and the edge portion also has a typical lamellar shape.

\section{Thermal Stability of Epoxy Resin/Graphene Oxide-Cobalt Nickel Phosphate Nanocomposites}

TG curves were used to further study the effect of GO$\mathrm{NiCoPO}_{3}$ nanosheets on $\mathrm{EP} / \mathrm{GO}-\mathrm{NiCoPO}$ nanocomposites. The TG curves of EP nanocomposites are shown in Figure 3, and the key data are listed in Table 2. Under the nitrogen atmosphere, pure EP begins to decompose $\left(\mathrm{T}_{5 \%}\right)$ at $354^{\circ} \mathrm{C}$ and the $50 \%$ mass loss decomposition temperature $\left(\mathrm{T}_{50 \%}\right)$ is $397^{\circ} \mathrm{C}$, showing that the main thermal decomposition stage is mainly attributed to oxidation of the main $\mathrm{C}$ chain in $\mathrm{EP}$, and the char residual is only $11.8 \mathrm{wt} \%$ at $700^{\circ} \mathrm{C}$. The addition of GO$\mathrm{NiCoPO}_{3}$ markedly improves the thermal stability of EP.

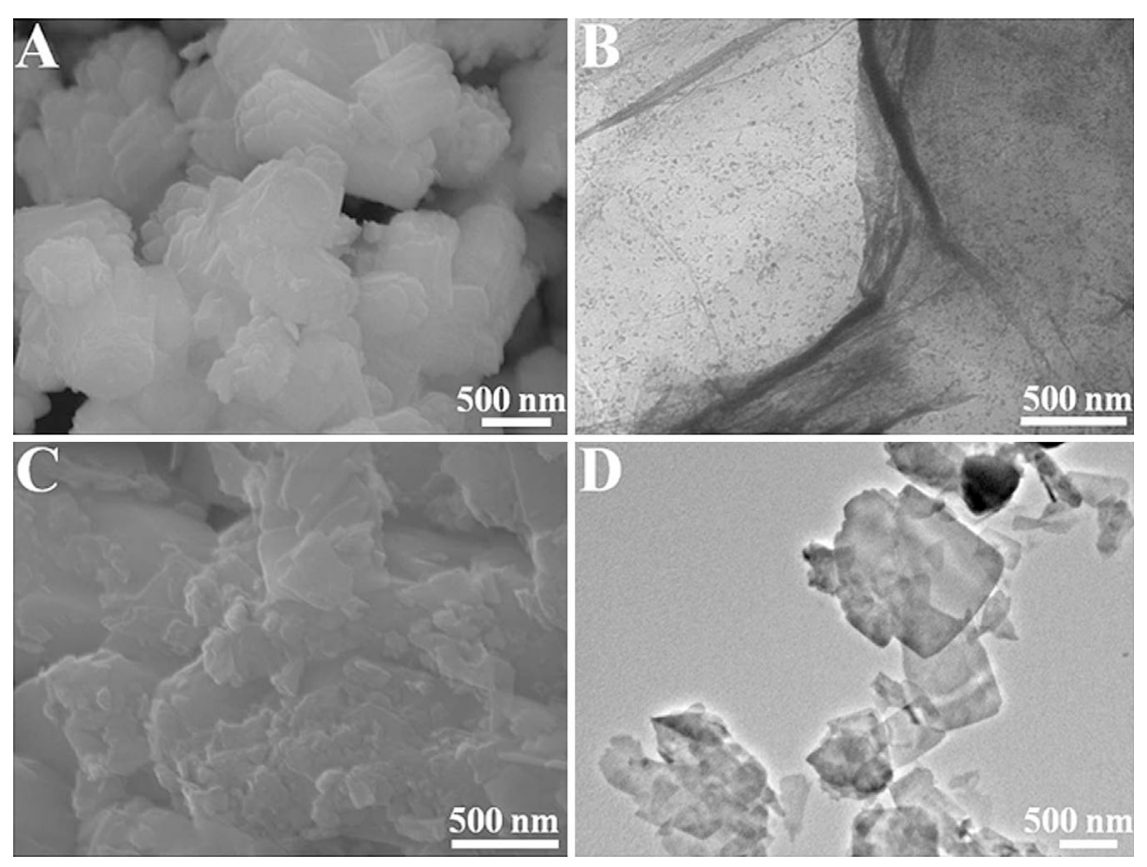

FIGURE 2 | (A) SEM image of $\mathrm{NiCoPO}_{3}$; (B) Transmission electron microscopy image of GO; (C) $\mathrm{SEM}_{\text {image of } \mathrm{GO}-\mathrm{NiCoPO}}$; (D) Transmission electron microscopy image of $\mathrm{GO}-\mathrm{NiCoPO}_{3}$. Go, graphene oxide; $\mathrm{NiCoPO}_{3}$, cobalt nickel phosphate. 


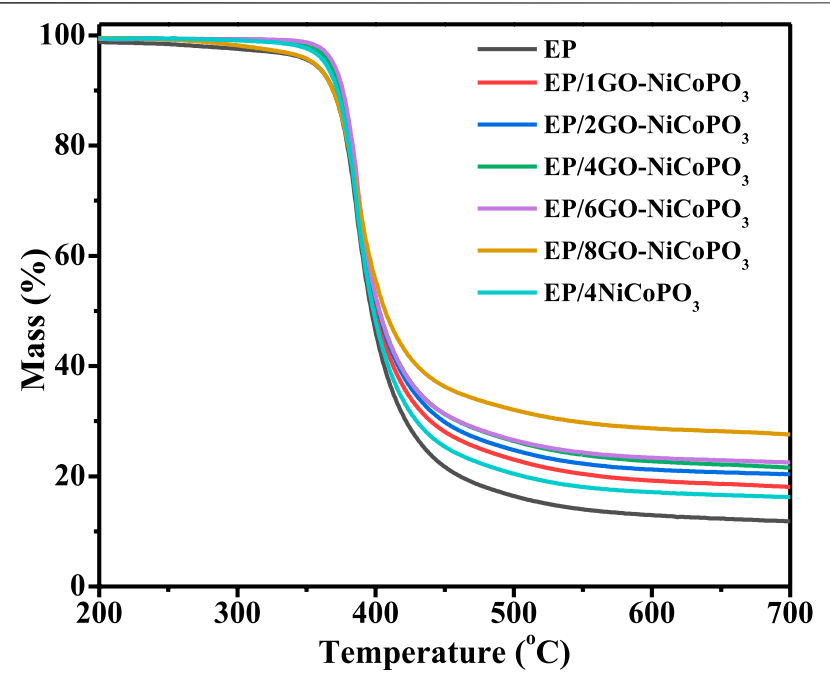

FIGURE 3 | Thermogravimetric curves of pure epoxy resin (EP) and EP nanocomposites.

When $1,2,4,6$, and 8 wt $\%$ GO-NiCoPO 3 nanosheets are added to $\mathrm{EP}$ nanocomposites, the $\mathrm{T}_{5 \%}$ and $\mathrm{T}_{50 \%}$ are increased to 366 , $367,365,369,360$, and $400^{\circ} \mathrm{C}, 402,402,402$, and $406^{\circ} \mathrm{C}$, respectively. The amount of residual char in EP/GO$\mathrm{NiCoPO}_{3}$ nanocomposites is also increased significantly by compared with that of pure EP. Particularly, the residue of EP nanocomposites with $8 \mathrm{wt} \% \mathrm{GO}-\mathrm{NiCoPO}_{3}$ reaches up to $27.6 \mathrm{wt} \%$ at $700^{\circ} \mathrm{C}$. Because of the lamellar structure of $\mathrm{GO}$, it has a barrier effect and prolongs the time for the combustible gas to escape from the matrix to the surface of EP/GO$\mathrm{NiCoPO}_{3}$ nanocomposites (Nine et al., 2017; Shi et al., 2018), so that the $\mathrm{Ni}$ ions and $\mathrm{Co}$ ions in $\mathrm{NiCoPO}_{3}$ have sufficient time to catalyze the carbonization of EP during the degradation process. The $\mathrm{EP} / 4 \mathrm{NiCoPO}_{3}$ nanocomposites are used as a comparison sample to further verify that the incorporation of $\mathrm{GO}-\mathrm{NiCoPO}_{3}$ in $\mathrm{EP}$ nanocomposites can improve its thermal stability. The $\mathrm{T}_{5 \%}$ and $\mathrm{T}_{50 \%}$ of $\mathrm{EP} /$ $4 \mathrm{NiCoPO}_{3}$ nanocomposites are 363 and $398^{\circ} \mathrm{C}$, and there are about $16.2 \mathrm{wt} \%$ char residues at $700^{\circ} \mathrm{C}$. Compared to $\mathrm{EP} / 4 \mathrm{NiCoPO}_{3}$ nanocomposites, the $\mathrm{T}_{5 \%}$ and $\mathrm{T}_{50 \%}$ values of $\mathrm{EP} / 4 \mathrm{GO}-\mathrm{NiCoPO}_{3}$ nanocomposites are obviously improved,

TABLE 2 | Thermogravimetric data of pure EP and EP nanocomposites.

\begin{tabular}{|c|c|c|c|}
\hline Sample & $\mathbf{T}_{5 \%}\left({ }^{\circ} \mathbf{C}\right)$ & $\mathrm{T}_{50 \%}\left({ }^{\circ} \mathrm{C}\right)$ & $\begin{array}{c}\text { Char residues at } 700 \mathrm{C} \\
\text { (wt\%) }\end{array}$ \\
\hline Pure EP & 354 & 397 & 11.8 \\
\hline $\mathrm{EP} / 1 \mathrm{Go}-\mathrm{NiCoPO}$ & 366 & 400 & 18.1 \\
\hline $\mathrm{EP} / 2 \mathrm{Go}-\mathrm{NiCoPO}$ & 367 & 402 & 20.4 \\
\hline $\mathrm{EP} / 4 \mathrm{Go}-\mathrm{NiCoPO}$ & 365 & 402 & 21.6 \\
\hline $\mathrm{EP} / 6 \mathrm{Go}-\mathrm{NiCoPO} 3$ & 369 & 402 & 22.5 \\
\hline $\mathrm{EP} / 8 \mathrm{Go}-\mathrm{NiCoPO}_{3}$ & 360 & 406 & 27.6 \\
\hline $\mathrm{EP} / 4 \mathrm{NiCoPO}_{3}$ & 363 & 398 & 16.2 \\
\hline
\end{tabular}

$E P$, epoxy resin; Go, graphene oxide; $\mathrm{NiCoPO}_{3}$, cobalt nickel phosphate.

TABLE 3 | LOI and UL-94 results of pure EP and EP nanocomposites.

Sample

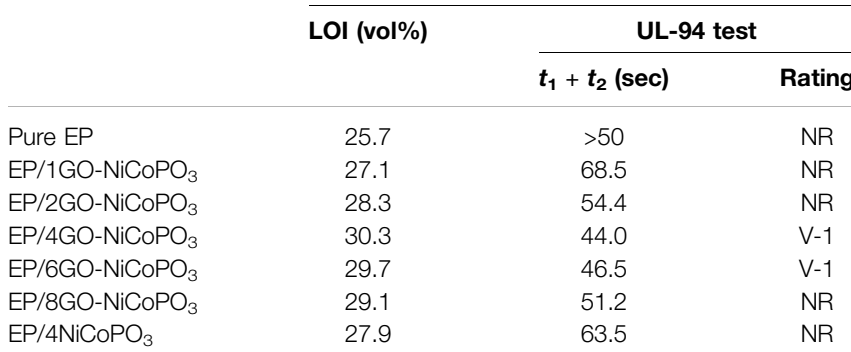

LOI, limiting oxygen index; $E P$, epoxy resin; Go, graphene oxide; $\mathrm{NiCOPO}_{3}$, cobalt nickel phosphate. Combustion performance of $\mathrm{EP} / \mathrm{GO}-\mathrm{NiCOPO}$, nanocomposites.

reaching 365 and $402^{\circ} \mathrm{C}$, respectively, and the residue reaches $21.6 \%$ at $700^{\circ} \mathrm{C}$. Compared with pure EP, the TG data of EP/ $4 \mathrm{NiCoPO}_{3}$ and $\mathrm{EP} / 4 \mathrm{GO}-\mathrm{NiCoPO}_{3}$ nanocomposites are significantly improved. The above results indicate that $\mathrm{NiCoPO}_{3}$ has excellent performance in catalyzing char formation, but the char layer is loose and weak. The layered GO can increase the viscosity of the polymer and combine the $\mathrm{Co}, \mathrm{Ni}$, and $\mathrm{P}$ in $\mathrm{NiCoPO}_{3}$ through covalent and non-covalent bonds (Cao et al., 2016; Xu et al., 2016), so that EP nanocomposites can be catalytic formed denser and richer char layer during thermal decomposition (Kong et al., 2018c).

UL-94 vertical burning tests and LOI are commonly used for evaluating the combustion properties of polymer composites. The results are shown in Table 3. The pure EP has no rating (NR) in the UL-94 test, and the LOI value is $25.8 \%$. When 1 and $2 \mathrm{wt} \% \mathrm{GO}-\mathrm{NiCoPO}_{3}$ are added into the EP matrix, the LOI values of $\mathrm{EP} / \mathrm{GO}-\mathrm{NiCoPO}_{3}$ nanocomposites are increased to 27.1 and $28.3 \%$, respectively. But they still have no UL-94 rating. With $\mathrm{GO}-\mathrm{NiCoPO}_{3}$ increasing to 4 and $6 \mathrm{wt} \%$, the LOI values of $\mathrm{EP} / \mathrm{GO}-\mathrm{NiCoPO}_{3}$ nanocomposites are increased to 30.3 and $29.7 \%$, respectively, and they can reach the V-1 level in UL-94 tests. However, with the amount of $\mathrm{GO}-\mathrm{NiCoPO}_{3}$ reaching $8 \mathrm{wt} \%$ in the $\mathrm{EP}$ matrix, the LOI value of $\mathrm{EP} / \mathrm{GO}-\mathrm{NiCoPO}_{3}$ nanocomposites is slightly reduced to $29.1 \%$, and it still has no UL-94 rating. This may be caused by the excessive addition of $\mathrm{GO}-\mathrm{NiCoPO}_{3}$, which cannot be uniformly dispersed in the EP matrix. The comparative sample $\mathrm{EP} / 4 \mathrm{NiCoPO}_{3}$ nanocomposites have a LOI value of $27.9 \%$, and it has no UL-94 rating, but EP/4GO-NiCoPO 3 nanocomposites reach $\mathrm{V}-1$ rating in UL-94 tests. The improvement in UL-94

TABLE 4 | Micro-combustion calorimetry data of pure EP and EP/GO-NiCoPO nanocomposites.

\begin{tabular}{lccc}
\hline Sample & PHRR $\mathbf{( W / g )}$ & THR $(\mathbf{K J} / \mathbf{g})$ & $\mathbf{T}_{\mathbf{p}}\left({ }^{\circ} \mathbf{C}\right)$ \\
\hline Pure EP & 560.9 & 39.4 & 417.6 \\
EP/1GO-NiCoPO & & \\
EP/4GO-NiCoPO $_{3}$ & 490.4 & 26.2 & 422.3 \\
EP/8GO-NiCoPO $_{3}$ & 458.6 & 22.0 & 415.6 \\
EP/4NiCoPO & 427.1 & 30.7 & 420.4
\end{tabular}

EP, epoxy resin; Go, graphene oxide; $\mathrm{NiCoPO}_{3}$, cobalt nickel phosphate. 

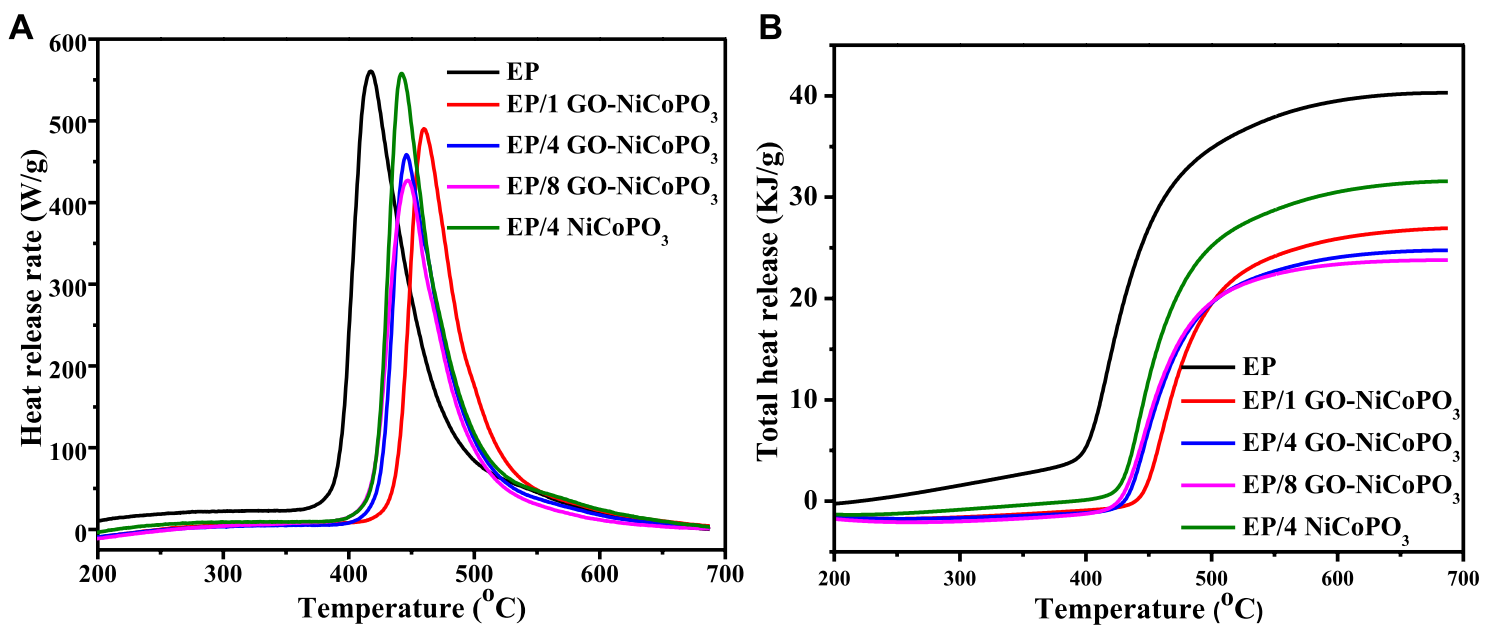

FIGURE 4 | (A) Heat release rate curves of EP/GO-NiCoPO 3 nanocomposites; (B) Total heat release curves of EP/GO-NiCoPO 3 nanocomposites. Go, graphene oxide; $\mathrm{NiCOPO}_{3}$, cobalt nickel phosphate.

rating and LOI values of $\mathrm{EP} / \mathrm{GO}-\mathrm{NiCoPO}_{3}$ nanocomposites is mainly attributed to the synergistic flame retardant effect of $\mathrm{GO}$ and $\mathrm{NiCoPO}_{3}$. On the one hand, GO containing a large number of organic groups (hydroxyl, carboxyl, epoxy, etc.) provides active sites that combine with transition metal ions in $\mathrm{NiCoPO}$, which not only play a barrier effect for protecting the unburned EP nanocomposites below but also catalytically convert toxic gases to nontoxic gases. On the other hand, the phosphate ions in $\mathrm{NiCoPO}_{3}$ are converted into metaphosphoric acid and polymetaphosphoric acid during the combustion process. Polymetaphosphoric acid has strong dehydration properties, which can dehydrate and char the polymer to form a char film to isolate the air, thereby changing the combustion process and improving the thermal stability of EP (Kong et al., 2017c; Wu et al., 2018; Guo et al., 2019).

MCC tests were performed to further verify the combustion performance of $\mathrm{EP} / \mathrm{GO}-\mathrm{NiCoPO}_{3}$ nanocomposites. The MCC tests were used to evaluate the potential fire hazard of EP/GO$\mathrm{NiCoPO}_{3}$ nanocomposites by measuring the HRR, the PHRR, and the THR (Shi et al., 2019). Detailed data are listed in Table 4, and the HRR and THR curves of pure EP and EP/GO-NiCoPO nanocomposites are shown in Figure 4. The PHRR value of pure $\mathrm{EP}$ is $560.9 \mathrm{~W} / \mathrm{g}$. Compared with pure EP, when 1, 4, and $8 \mathrm{wt} \%$ GO-NiCoPO 3 are added into the EP matrix, the PHRR values are decreased to $490.4,458.6$, and $427.1 \mathrm{~W} / \mathrm{g}$, respectively, reducing about $12.6,18.2$, and $23.9 \%$, respectively. The THR values of EP/ $1 \mathrm{GO}-\mathrm{NiCoPO}_{3}, \mathrm{EP} / 4 \mathrm{GO}-\mathrm{NiCoPO}_{3}$, and $\mathrm{EP} / 8 \mathrm{GO}-\mathrm{NiCoPO}_{3}$ nanocomposites are $26.2,24$, and $22.9 \mathrm{KJ} / \mathrm{g}$, reducing about $33.5,39.1$, and $41.9 \%$, respectively. This fully indicates that GO-NiCoPO 3 can promote the formation of a dense and strong char layer on the surface of the polymer and prevent the transfer of external heat and oxygen to the EP matrix, inhibiting polymer combustion and reducing heat release. However, the PHRR value $(557.8 \mathrm{~W} / \mathrm{g})$ and THR value
$(30.7 \mathrm{KJ} / \mathrm{g})$ of $\mathrm{EP} / 4 \mathrm{NiCoPO}_{3}$ nanocomposites are higher than those of $\mathrm{EP} / 4 \mathrm{GO}-\mathrm{NiCoPO}$ and slightly lower than those of pure EP. This may be due to the addition of $\mathrm{NiCoPO}_{3}$; although it has a certain catalytic char formation, the char layer formed is thin and sparse, which has a poor barrier effect so that the heat release amount is not significantly reduced. When $\mathrm{NiCoPO}_{3}$ modified by $\mathrm{GO}$ with a rich $\mathrm{C}$ structure is added to the EP matrix, the viscosity of the $\mathrm{EP} / \mathrm{GO}-\mathrm{NiCoPO}_{3}$ polymer increases and reduces the burning rates, which provides sufficient time to catalyze the carbonization of the matrix in the polymer (Wang et al., 2017; Feng et al., 2018). The char layer, whose quantity and quality have been significantly changed, can cover the polymer surface, prevent heat from escaping, inhibit the combustion, and enhance the flame retardant performance of the composites (Zhang et al., 2016; Kong et al., 2017b).

\section{CONCLUSIONS}

In summary, $\mathrm{NiCoPO}_{3}$ nanosheets and $\mathrm{GO}-\mathrm{NiCoPO}_{3}$ were synthesized by a simple solvothermal method. The TG results showed that the addition of $\mathrm{GO}-\mathrm{NiCoPO}_{3}$ promoted char formation and enhanced the thermal stability of the polymer at high temperatures. The LOI and UL-94 data showed that when $4 \mathrm{wt} \% \mathrm{GO}-\mathrm{NiCoPO}_{3}$ was added, the LOI value was as high as $30.3 \%$, and it reached UL- $94 \mathrm{~V}-1$ rating. The MCC results showed that the addition of $\mathrm{GO}-\mathrm{NiCoPO}_{3}$ significantly reduced the PHRR and THR values of EP nanocomposites. Compared with pure $\mathrm{EP}$, the THR value of $\mathrm{EP} / 8 \mathrm{GO}-\mathrm{NiCoPO}_{3}$ nanocomposites was decreased by $41.9 \%$. These results indicated that $\mathrm{GO}-\mathrm{NiCoPO}_{3}$ increased the flame retardancy of $\mathrm{EP} / \mathrm{GO}-\mathrm{NiCoPO}_{3}$ nanocomposites to some extent. This was mainly due to the fact that $\mathrm{GO}-\mathrm{NiCoPO}_{3}$ formed dense carbonaceous protection layers to reduce heat transfer, inhibit combustion, and improve thermal stability of composites. 


\section{DATA AVAILABILITY STATEMENT}

All datasets presented in this study are included in the article.

\section{AUTHOR CONTRIBUTIONS}

QK and JZ conceived and designed the study and experiment plan and wrote the manuscript. CZ drafted the manuscript. MZ and $\mathrm{TZ}$ analyzed the experimental results.

\section{REFERENCES}

Asabina, E. A., Maiorov, P. A., Pet'kov, V. I., Koval'skii, A. M., and Borovikova, E. Y. (2019). Phosphates of zirconium and metals (Ni, Cu, Co, and $\mathrm{Mn}$ ) in the oxidation state of +2: synthesis and structure. Russ. J. Inorg. Chem. 64, 290-295. doi:10.1134/s0036023619030021

Cai, W., Feng, X., Hu, W., Pan, Y., Hu, Y., and Gong, X. (2016). Functionalized graphene from electrochemical exfoliation for thermoplastic polyurethane: thermal stability, mechanical properties, and flame retardancy. Ind. Eng. Chem. Res. 55, 10681-10689. doi:10.1021/acs.iecr.6b02579

Cao, Y., Li, G., and Li, X. (2016). Graphene/layered double hydroxide nanocomposite: properties, synthesis, and applications. Chem. Eng. J. 292, 207-223. doi:10.1016/j.cej.2016.01.114

Chen, Y. J., Wu, X. D., and Qian, L. J. (2020). Flame-retardant behavior and protective layer effect of phosphazene-triazine bi-group flame retardant on polycarbonate. J. Appl. Polym. Sci. e49523. doi:10.1002/app.49523

Cote, L. J., Kim, J., Tung, V. C., Luo, J. Y., Kim, F., and Huang, J. X. (2011). Graphene oxide as surfactant sheets. Pure Appl. Chem. 83, 95-110. doi:10.1351/ PAC-CON-10-10-25

Ding, J., Zhang, Y., Zhang, X., Kong, Q., Zhang, J., Liu, H., et al. (2020). Improving the flame-retardant efficiency of layered double hydroxide with disodium phenylphosphate for epoxy resin. J. Therm. Anal. Calorim. 140, 149-156. doi:10.1007/s10973-019-08372-9

Feng, Y., Han, G., Wang, B., Zhou, X., Ma, J., Ye, Y., et al. (2020). Multiple synergistic effects of graphene-based hybrid and hexagonal born nitride in enhancing thermal conductivity and flame retardancy of epoxy. Chem. Eng. J. 379, 122402. doi:10.1016/j.cej.2019.122402

Feng, Y., Li, X., Zhao, X., Ye, Y., Zhou, X., Liu, H., et al. (2018). Synergetic improvement in thermal conductivity and flame retardancy of epoxy/silver nanowires composites by incorporating "Branch-Like" flame-retardant functionalized graphene. ACS Appl. Mater. Interfaces 10, 21628-21641. doi:10.1021/acsami.8b05221

Feng, Y., Yuan, L., Liang, G., and Gu, A. (2019). Phosphorus-free boron nitride/ cerium oxide hybrid: a synergistic flame retardant and smoke suppressant for thermally resistant cyanate ester resin. Polym. Adv. Technol. 30, 2340-2352. doi:10.1002/pat.4675

Guo, X., Qian, C., Shi, R., Zhang, W., Xu, F., Qian, S., et al. (2019). Biomorphic $\mathrm{CoNC} / \mathrm{CoO} \mathrm{x}$ composite derived from natural chloroplasts as efficient electrocatalyst for oxygen reduction reaction. Small 15, 1804855. doi:10. 1002/smll.201804855

Guo, X., Qian, C., Wan, X., Zhang, W., Zhu, H., Zhang, J., et al. (2020). Facile in situ fabrication of biomorphic Co2P-Co3O $4 / \mathrm{rGO} / \mathrm{C}$ as an efficient electrocatalyst for the oxygen reduction reaction. Nanoscale 12, 4374-4382. doi:10.1039/c9nr10785a

Huang, G., Ni, Z., Chen, G., Li, G., and Zhao, Y. (2016). Investigation of irradiated graphene oxide/ultra-high-molecular-weight polyethylene nanocomposites by ESR and FTIR spectroscopy. Fullerenes Nanotub. Carbon Nanostruct. 24, 698-704. doi:10.1080/1536383x.2016.1229310

Huang, N. M., Lim, H. N., Chia, C. H., Yarmo, M. A., and Muhamad, M. R. (2011). Simple room-temperature preparation of high-yield large-area graphene oxide. Int. J. Nanomed. 6, 3443-3448. doi:10.2147/ijn.s26812

Kong, Q., Sun, Y., Zhang, C., Guan, H., Zhang, J., Wang, D.-Y., et al. (2019a). Ultrathin iron phenyl phosphonate nanosheets with appropriate thermal stability for improving fire safety in epoxy. Compos. Sci. Technol. 182, 107748. doi:10.1016/j.compscitech.2019.107748

\section{FUNDING}

This research is funded by the National Natural Science Foundation of China (51603091), Natural Science Foundation of Jiangsu Province (BK20181469), Science and Technology Planning Social Development Project of Zhenjiang City (SSH20190140049), and the Open Project Program of Key Laboratory of Eco-textiles, Ministry of Education, Jiangnan University (No. KLET2006).

Kong, Q., Zhang, M., Zhao, S., Yuan, Z., Yu, S., Zhang, F., et al. (2019b). Improving fire safety of epoxy resin with alkyl glycoside modified CuAl-layered double hydroxide. J. Nanosci. Nanotechnol. 19, 4571-4577. doi:10.1166/jnn.2019. 16495

Kong, Q., Zhang, Y., Zhang, X., Xiang, B., Yi, Y., Zhu, J., et al. (2019c). Functionalized montmorillonite intercalation iron compounds for improving flame retardancy of epoxy resin nanocomposites. J. Nanosci. Nanotechnol. 19, 5803-5809. doi:10.1166/jnn.2019.16540

Kong, Q., Wu, T., Liu, H., Zhang, Y., Zhang, M., Cai, Y., et al. (2018a). Graphene oxide nanocoating prevents flame spread on polyurethane sponge. J. Nanosci. Nanotechnol. 18, 5105-5112. doi:10.1166/jnn.2018.15284

Kong, Q., Wu, T., Wang, J., Liu, H., and Zhang, J. (2018b). Improving the thermal stability and flame retardancy of PP/IFR composites by NiAl-layered double hydroxide. J. Nanosci. Nanotechnol. 18, 3660-3665. doi:10.1166/jnn.2018. 14679

Kong, Q., Wu, T., Zhang, J., and Wang, D.-Y. (2018c). Simultaneously improving flame retardancy and dynamic mechanical properties of epoxy resin nanocomposites through layered copper phenylphosphate. Compos. Sci. Technol. 154, 136-144. doi:10.1016/j.compscitech.2017.10.013

Kong, Q., Wu, T., Tang, Y., Xiong, L., Liu, H., Zhang, J., et al. (2017a). Improving thermal and flame retardant properties of epoxy resin with organic $\mathrm{NiFe}$ layered double hydroxide-carbon nanotubes hybrids. Chin. J. Chem. 35, 1875-1880. doi:10.1002/cjoc.201700313

Kong, Q., Wu, T., Zhang, H., Zhang, Y., Zhang, M., Si, T., et al. (2017b). Improving flame retardancy of IFR/PP composites through the synergistic effect of organic montmorillonite intercalation cobalt hydroxides modified by acidified chitosan. Appl. Clay Sci. 146, 230-237. doi:10.1016/j.clay.2017.05.048

Kong, Q., Zhang, H., Zheng, L., Wang, D.-Y., and Zhang, J. (2017c). Effect on thermal and combustion behaviors of montmorillonite intercalation nickel compounds in polypropylene/IFR system. Polym. Adv. Technol. 28, 965-970. doi:10.1002/pat.3823

Li, B., Gu, P., Feng, Y., Zhang, G., Huang, K., Xue, H., et al. (2017). Ultrathin nickelcobalt phosphate 2D nanosheets for electrochemical energy storage under aqueous/solid-state electrolyte. Adv. Funct. Mater. 27, 1605784. doi:10.1002/ adfm. 201605784

Li, Z., Zhang, J., Dufosse, F., and Wang, D.-Y. (2018). Ultrafine nickel nanocatalystengineering of an organic layered double hydroxide towards a super-efficient fire-safe epoxy resin via interfacial catalysis. J. Mater. Chem. 6, 8488-8498. doi:10.1039/c8ta00910d

Liao, S.-H., Liu, P.-L., Hsiao, M.-C., Teng, C.-C., Wang, C.-A., Ger, M.-D., et al. (2012). One-step reduction and functionalization of graphene oxide with phosphorus-based compound to produce flame-retardant epoxy nanocomposite. Ind. Eng. Chem. Res. 51, 4573-4581. doi:10.1021/ie2026647

Mu, X., Yuan, B., Feng, X., Qiu, S., Song, L., and Hu, Y. (2016). The effect of doped heteroatoms (nitrogen, boron, phosphorus) on inhibition thermal oxidation of reduced graphene oxide. RSC $A d v$. 6, 105021-105029. doi:10. 1039/c6ra21329d

Nie, S., Jin, D., Xu, Y., Han, C., Dong, X., and Yang, J.-n. (2020). Effect of a flowerlike nickel phyllosilicate-containing iron on the thermal stability and flame retardancy of epoxy resin. J. Mater. Res. Technol. 9, 10189. doi:10.1016/j.jmrt. 2020.07.021

Nine, M. J., Tran, D. N. H., Tung, T. T., Kabiri, S., and Losic, D. (2017). Grapheneborate as an efficient fire retardant for cellulosic materials with multiple and synergetic modes of action. ACS Appl. Mater. Interfaces 9, 10160-10168. doi:10. 1021/acsami.7b00572 
Peng, C., Chen, T., Zeng, B., Chen, G., Yuan, C., Xu, Y., et al. (2020). Anderson-type polyoxometalate-based hybrid with high flame retardant efficiency for the preparation of multifunctional epoxy resin nanocomposites. Compos. B Eng. 186, 107780. doi:10.1016/j.compositesb.2020.107780

Reuter, J., Greiner, L., Kukla, P., and Döring, M. (2020). Efficient flame retardant interplay of unsaturated polyester resin formulations based on ammonium polyphosphate. Polym. Degrad. Stabil. 178, 109134. doi:10.1016/j. polymdegradstab.2020.109134

Shi, X., Peng, X., Zhu, J., Lin, G., and Kuang, T. (2018). Synthesis of DOPO-HQfunctionalized graphene oxide as a novel and efficient flame retardant and its application on polylactic acid: thermal property, flame retardancy, and mechanical performance. J. Colloid Interface Sci. 524, 267-278. doi:10.1016/ j.jcis.2018.04.016

Shi, Y., Liu, C., Duan, Z., Yu, B., Liu, M., and Song, P. (2020). Interface engineering of MXene towards super-tough and strong polymer nanocomposites with high ductility and excellent fire safety. Chem. Eng. J. 399, 125829. doi:10.1016/j.cej. 2020.125829

Shi, Y., Liu, C., Liu, L., Fu, L., Yu, B., Lv, Y., et al. (2019). Strengthening, toughing and thermally stable ultra-thin MXene nanosheets/polypropylene nanocomposites via nanoconfinement. Chem. Eng. J. 378, 122267. doi:10. 1016/j.cej.2019.122267

Si, Y., and Samulski, E. T. (2008). Exfoliated graphene separated by platinum nanoparticles. Chem. Mater. 20, 6792-6797. doi:10.1021/cm801356a

Stobinski, L., Lesiak, B., Malolepszy, A., Mazurkiewicz, M., Mierzwa, B., Zemek, J., et al. (2014). Graphene oxide and reduced graphene oxide studied by the XRD, TEM and electron spectroscopy methods. J. Electron. Spectrosc. Relat. Phenom. 195, 145-154. doi:10.1016/j.elspec.2014.07.003/

Sun, Z., Hou, Y., Hu, Y., and Hu, W. (2018). Effect of additive phosphorusnitrogen containing flame retardant on char formation and flame retardancy of epoxy resin. Mater. Chem. Phys. 214, 154-164. doi:10.1016/j.matchemphys. 2018.04.065

Tang, G., Liu, X., Yang, Y., Chen, D., Zhang, H., Zhou, L., et al. (2020a). Phosphorus-containing silane modified steel slag waste to reduce fire hazards of rigid polyurethane foams. Adv. Powder Technol. 31, 1420-1430. doi:10.1016/j.apt.2020.01.019

Tang, G., Liu, X., Zhou, L., Zhang, P., Deng, D., and Jiang, H. (2020b). Steel slag waste combined with melamine pyrophosphate as a flame retardant for rigid polyurethane foams. Adv. Powder Technol. 31, 279-286. doi:10.1016/j.apt.2019. 10.020

Tang, G., Zhou, L., Zhang, P., Han, Z., Chen, D., Liu, X., et al. (2020c). Effect of aluminum diethylphosphinate on flame retardant and thermal properties of rigid polyurethane foam composites. J. Therm. Anal. Calorim. 140, 625-636. doi:10.1007/s10973-019-08897-z

Wang, X., Kalali, E. N., Wan, J.-T., and Wang, D.-Y. (2017). Carbon-family materials for flame retardant polymeric materials. Prog. Polym. Sci. 69, 22-46. doi:10.1016/j.progpolymsci.2017.02.001

Wu, T., Kong, Q., Zhang, H., and Zhang, J. (2018). Thermal stability and flame retardancy of polypropylene/NiAl layered double hydroxide nanocomposites. J. Nanosci. Nanotechnol. 18, 1051-1056. doi:10.1166/jnn.2018.14107

Xu, W., Wang, X., Wu, X., Li, W., and Cheng, C. (2019). Organic-inorganic dual modified graphene: improving the dispersibility of graphene in epoxy resin and the fire safety of epoxy resin. Polym. Degrad. Stabil. 165, 80-91. doi:10.1016/j. polymdegradstab.2019.04.023

Xu, W., Zhang, B., Xu, B., and Li, A. (2016). The flame retardancy and smoke suppression effect of heptaheptamolybdate modified reduced graphene oxide/ layered double hydroxide hybrids on polyurethane elastomer. Compos. Appl. Sci. Manuf. 91, 30-40. doi:10.1016/j.compositesa.2016.09.013

Xu, X., Wang, S., Ma, S., Yuan, W., Li, Q., Feng, J., et al. (2019). Vanillin-derived phosphorus-containing compounds and ammonium polyphosphate as green fire-resistant systems for epoxy resins with balanced properties. Polym. Adv. Technol. 30, 264-278. doi:10.1002/pat.4461

Xue, Y., Yu, T., Chen, J., Wan, X., Cai, X., Guo, X., et al. (2020). Fabrication of GeO2 microspheres/hierarchical porous $\mathrm{N}$-doped carbon with superior cyclic stability for Li-ion batteries. J. Solid State Chem. 286, 121303. doi:10.1016/j.jssc.2020. 121303

Yang, G., Wu, W.-H., Wang, Y.-H., Jiao, Y.-H., Lu, L.-Y., Qu, H.-Q., et al. (2019). Synthesis of a novel phosphazene-based flame retardant with active amine groups and its application in reducing the fire hazard of epoxy resin. J. Hazard Mater. 366, 78-87. doi:10.1016/j.jhazmat.2018.11.093

Yu, D., Wen, S., Yang, J., Wang, J., Chen, Y., Luo, J., et al. (2017). RGO modified ZnAl-LDH as epoxy nanostructure filler: a novel synthetic approach to anticorrosive waterborne coating. Surf. Coating. Technol. 326, 207-215. doi:10.1016/j.surfcoat.2017.07.053

Yu, Z., Di, H., Ma, Y., He, Y., Liang, L., Lv, L., et al. (2015). Preparation of graphene oxide modified by titanium dioxide to enhance the anti-corrosion performance of epoxy coatings. Surf. Coating. Technol. 276, 471-478. doi:10.1016/j.surfcoat. 2015.06.027

Yue, X., Li, C., Ni, Y., Xu, Y., and Wang, J. (2019). Flame retardant nanocomposites based on 2D layered nanomaterials: a review. J. Mater. Sci. 54, 13070-13105. doi:10.1007/s10853-019-03841-w

Zhang, D., Guo, X., Tong, X., Chen, Y., Duan, M., Shi, J., et al. (2020). Highperformance battery-type supercapacitor based on porous biocarbon and biocarbon supported Ni-Co layered double hydroxide. J. Alloys Compd. Compd. 837, 155529. doi:10.1016/j.jallcom.2020.155529

Zhang, J., Kong, Q., and Wang, D.-Y. (2018). Simultaneously improving the fire safety and mechanical properties of epoxy resin with Fe-CNTs via large-scale preparation. J. Mater. Chem. 6, 6376-6386. doi:10.1039/c7ta10961j

Zhang, J., Kong, Q., Yang, L., and Wang, D.-Y. (2016). Few layered $\mathrm{Co}(\mathrm{OH})_{2}$ ultrathin nanosheet-based polyurethane nanocomposites with reduced fire hazard: from eco-friendly flame retardance to sustainable recycling. Green Chem. 18, 3066-3074. doi:10.1039/c5gc03048j

Zhang, Q., Li, Z., Li, X., Yu, L., Zhang, Z., and Wu, Z. (2019). Preparation of cobalt ferrite nanoparticle-decorated boron nitride nanosheet flame retardant and its flame retardancy in epoxy resin. Nano 14, 1950063. doi:1010.1142/ s1793292019500632

Zheng, L., Wu, T., Kong, Q., Zhang, J., and Liu, H. (2017). Improving flame retardancy of $\mathrm{PP} / \mathrm{MH} / \mathrm{RP}$ composites through synergistic effect of organic CoAl-layered double hydroxide. J. Therm. Anal. Calorim. 129, 1039-1046. doi:10.1007/s10973-017-6231-6

Zhou, K., Gao, R., and Qian, X. (2017). Self-assembly of exfoliated molybdenum disulfide (MoS 2 ) nanosheets and layered double hydroxide (LDH): towards reducing fire hazards of epoxy. J. Hazard Mater. 338, 343-355. doi:10.1016/j. jhazmat.2017.05.046

Zhou, T., Wu, T., Xiang, H., Li, Z., Xu, Z., Kong, Q., et al. (2019). Simultaneously improving flame retardancy and dynamic mechanical properties of epoxy resin nanocomposites through synergistic effect of zirconium phenylphosphate and POSS. J. Therm. Anal. Calorim. 135, 2117-2124. doi:10.1007/s10973-018-73874

Zhu, Y., Murali, S., Cai, W., Li, X., Suk, J. W., Potts, J. R., et al. (2010). Graphene and graphene oxide: synthesis, properties, and applications. Adv. Mater. 22, 3906-3924. doi:10.1002/adma.201001068.

Zhu, Z., Lin, P., Wang, H., Wang, L., Yu, B., and Yang, F. (2020). A facile one-step synthesis of highly efficient melamine salt reactive flame retardant for epoxy resin. J. Mater. Sci. 55, 12836-12847. doi:10.1007/s10853-020-04935-6

Conflict of Interest: The authors declare that the research was conducted in the absence of any commercial or financial relationships that could be construed as a potential conflict of interest.

Copyright $\odot 2020$ Kong, Zhang, Zheng, Zhang, Zhou and Zhang. This is an openaccess article distributed under the terms of the Creative Commons Attribution License (CC BY). The use, distribution or reproduction in other forums is permitted, provided the original author(s) and the copyright owner(s) are credited and that the original publication in this journal is cited, in accordance with accepted academic practice. No use, distribution or reproduction is permitted which does not comply with these terms. 